\title{
Poder mediático y notoriedad periodística: Bernardo Neustadt y el periodismo político en la década de 1990
}

\begin{abstract}
Micaela Baldoni' iD
IFacultad de Ciencias Sociales de la Universidad de Buenos Aires, Buenos Aires, Argentina.

RESUMEN Introducción: En el marco de las reconfiguraciones que sufrieron el campo político y periodístico en los años noventa en la Argentina, el presente estudio se interroga por el creciente poder que comenzaron a detentar los periodistas en la construcción de consensos sociales y en la configuración de escenarios político-mediáticos. Materiales y Métodos: Para ello, realiza un análisis sociohistórico de un caso de estudio de carácter ejemplar. El trabajo reconstruye la trayectoria profesional del periodista Bernardo Neustadt, quien se convirtió en pionero y vedette del periodismo político televisivo en aquellos años. Asimismo, se concentra en las características singulares del acto político promovido por este actor en 1990, conocido como la "Plaza del Sí", el cual contribuyó a la legitimación del modelo neoliberal impulsado por el gobierno de turno. En función de estos objetivos, se relevaron fuentes complementarias: archivos de prensa, biografías, libros periodísticos, materiales audiovisuales y entrevistas semiestructuradas realizadas a periodistas e informantes claves. Resultados: El estudio da cuenta de cómo, junto a la creciente gravitación de los medios audiovisuales, la notoriedad mediática se convirtió en una forma de capital simbólico, la cual comenzó a operar en el campo político-periodístico como una forma de prestigio y legitimidad social. La detentación de esta forma de capital posibilitó así que ciertos periodistas se convirtieran en personalidades públicas cuyo poder se fundaba en la masividad de sus audiencias. Discusión: El artículo convoca así a interrogarse sobre los roles desplegados por los periodistas en la arena pública como productores de opinión y sobre las distintas formas en que puede ejercerse el poder mediático, en particular en coyunturas signadas por el descrédito de las instituciones y organizaciones políticas.
\end{abstract}

PALABRAS-CLAVE: periodismo político; poder mediático; opinión pública; mediatización de la política; notoriedad.

Recibido en el 12 de Junio de 2017. Aprobado en el 17 de Octubre de 2018. Revisado por la autora en el 23 Deciembre de 2018.

\section{Introducción ${ }^{1}$}

${ }^{1}$ Agradecemos las sugerencias y comentarios de los dictaminadores anónimos de la Revista de Sociologia e Política.
$\mathrm{E}$ 17 de abril de 1990, la imagen de la Plaza de Mayo ocupó otra vez las tapas de los principales diarios de Buenos Aires. Banderas e insignias blanquicelestes teñían a la multitud reunida en uno de los principales espacios públicos del país. Los titulares señalaban que el carácter multitudinario de la "Plaza del Sí", como se la denominó por su posición favorable al gobierno de turno, se traducía en un contundente apoyo a las políticas de reforma y de privatizaciones, que intentaba emprender el entonces presidente Carlos Menem. El éxito del acto era incuestionable. Las estimaciones partían de 60.000 manifestantes, llegando hasta las 200.000 personas, según los cálculos más optimistas. Los cánticos "Argentina, Argentina" y "Menem querido, el pueblo está contigo" resonaban en la boca de los manifestantes, sin identificaciones partidarias.

Desde el palco, frente a la multitud, el presidente anunció airoso, tras aclarar que "no venía a hablar en nombre de un partido ni de un gobierno", que estaba "naciendo una nueva Argentina". El cuadro del palco se completaba con los principales funcionarios políticos del entorno presidencial y figuras del mundo televisivo y del espectáculo. Entre ellas, se destacaba la del periodista Bernardo Neustadt, que había logrado atraer a las lentes de los fotógrafos de los distintos medios y cuya imagen, en varias coberturas, opacó incluso a la del presidente 
${ }^{2}$ Champagne retoma aquí la noción de campo de Bourdieu, la cual refiere a un espacio estructurado de posiciones en el cual los actores compiten por un capital específico. No obstante, la laxitud de las fronteras y la débil autonomía del ámbito periodístico respecto a otros espacios, como el político, lleva al autor a ampliar y redefinir esta noción, de manera de dar cuenta de esas interrelaciones (Champagne 2007).
Menem. Neustadt, "el dueño del palco" (Nueva Fuerza 1990), como lo definió uno de los matutinos que colocó su foto en tapa, no sólo era considerado el ideólogo de la marcha por el "sî", sino también el principal responsable de la masividad que alcanzó la convocatoria. En los días subsiguientes, diarios y revistas políticas se ocuparon de analizar el "fenómeno Neustadt", ya sea entrevistándolo o pidiendo la opinión de especialistas en comunicación para que ponderasen su poder e influencia.

Ahora bien, ¿cómo llegó un periodista a ocupar una posición protagónica en la promoción y organización de un acto político de carácter masivo? ¿Cuáles eran las fuentes de su poder y en qué tipo de alianzas con actores políticos y mediáticos se había sustentado su participación? Más aún, ¿de qué manera el rol desplegado por Neustadt y las características inéditas de este acontecimiento pueden considerarse un caso liminar del creciente poder que, en aquellos años, comenzaban a detentar ciertos periodistas en la construcción de consensos sociales y en la configuración de escenarios político-mediáticos?

A partir de estos interrogantes, en base a un estudio de caso, este artículo se propone comprender la emergencia de esta figura periodística y su creciente poder en la arena pública. Tanto la trayectoria de Neustadt, como el evento político estudiado, condensan algunas de las reconfiguraciones que comenzaron a delinear, durante la década del noventa, el campo político-periodístico. Siguiendo a Champagne (2002, pp.19-23), esta noción, derivada de los esquemas conceptuales propuestos por Bourdieu ${ }^{2}$, permite delimitar un espacio de imbricación en el cual los periodistas interactúan con otros actores, y la competencia es ante todo una lucha de orden simbólico por la interpretación "verdadera" de la coyuntura política.

Entre las reconfiguraciones suscitadas en este ámbito, nos centramos en el incipiente proceso de vedettización de la profesión, que se expresó en la conformación de una nueva élite periodística distinguida por su visibilidad y por su capacidad de constituir opinión. En particular, procuramos indagar el modo en que la notoriedad mediática devino un elemento de jerarquización y prestigio, que permitió a estos profesionales de los medios erigirse como voceros o representantes del público, en un contexto signado por la reestructuración privatista del sistema mediático y por el descrédito de las instituciones políticas.

Con el objeto de analizar cómo emerge esta nueva figura periodística, en el primer apartado, reconstruimos el derrotero mediante el cual Neustadt devino una vedette de la profesión, y el modo en qué contribuyó a instituir este nuevo modelo de periodismo. En el segundo apartado, nos ocupamos de analizar de qué modo, hacia fines de los años ochenta, en un contexto de crisis política y económica, el periodista amplió y conformó un público "propio", convirtiéndose en traductor y divulgador de las recetas neoliberales propuestas por economistas y dirigentes políticos de aquel entonces. En el tercer apartado, mostramos cómo el programa televisivo de Neustadt, "Tiempo Nuevo", se convirtió en el ámbito a partir del cual se establecieron las alianzas entre el periodista y los actores políticos que organizaron la Plaza del Sí, constituyendo una de las arenas que escenificaban las nacientes lógicas de la mediatización de la política. En el cuarto apartado, nos concentramos en dicha manifestación y destacamos el carácter inédito del protagonismo que alcanzaron algunos actores mediáticos en la promoción de un acto público y masivo, cuya convocatoria se asentó en una retórica "apartidaria" y anclada en una lógica de "despolitización". Por último, nos concentramos en el declive de la figura de Neustadt hacia fines de la década y en cómo la pérdida de su público revela la reconfiguración de los criterios deontológicos del campo periodístico. 


\section{Vedettización, notoriedad y poder mediático}

${ }^{3}$ Como sostiene Bourdieu (1979), frente a los diferentes tipos de capital que operan al interior de los campos, aquellos que devienen capitales simbólicos que confieren prestigio o estatus a los agentes que los portan. legítimos funcionan como

El periodista Bernardo Neustadt (1925-2008) constituye una figura pionera de un modelo de periodismo político que ganó cada vez más terreno en los años noventa, gracias a la generalización de los medios audiovisuales, particularmente de la televisión, y de sus lógicas comerciales. En este modelo, el periodista deviene una suerte de vedette de la profesión. Este termino de origen francés, al igual que sus expresiones en otros idiomas (star o superstar, estrella), se consagró con la conformación del modelo del star system hollywoodense, a través del cual la industria cinematográfica convierte a personalidades de renombre en marcas o mercancías (Morin 1984 [1957]; Dyer 2007 [1979]). Desde mediados del siglo XX, a medida que la televisión extendió su radio de penetración, las lógicas de la vedettización también se desarrollaron en la pantalla chica, permitiendo que otras figuras además de los actores devinieran figuras célebres (Driessens 2013; Esquenazi 2009; Evans 2005; Pasquier \& Tsikounas 2015). Para Rieffel (1989), en su estudio sobre el caso francés, los periodistas que se convierten en vedettes constituyen una suerte de nueva élite profesional que comprende, como señalan Le Grignou y Neveu (2017, p. 28), un sector minoritario y particularmente visible, que acumula "renombre, estabilidad, capital social y remuneraciones altas", y cuya legitimidad profesional y social es un indicador de la creciente impronta de los medios audiovisuales en el campo periodístico.

Esta posición destacada y jerarquizada se asienta en la detentación de un capital simbólico ${ }^{3}$ específico, al que denominamos notoriedad mediática. La notoriedad mediática se expresa en dos cualidades que distinguen a este tipo de figura periodística del resto de sus colegas: por un lado, en el hecho de ser un periodista (re)conocido y seguido por un público masivo, debido a sus recurrentes exposiciones mediáticas en el ejercicio de su profesión, y, por otro, en su capacidad de intervenir en nombre propio con el fin de constituir opinión en los escenarios político-mediáticos e, incluso, configurarlos. En este sentido, la notoriedad deviene un capital simbólico en el momento en que comienza a operar en el campo político-periodístico como un criterio de legitimación que transforma a ciertos periodistas en personalidades públicas. A su vez, la notoriedad constituye una forma de poder mediático, en el sentido en que lo entiende Couldry (2003). En tanto "metacapital", que trasciende las fronteras de su propio campo, posibilita que aquellos periodistas que detentan esa cualidad cuenten con una mayor capacidad de "legitimación mediática de las representaciones y categorías de comprensión del mundo social que están disponibles para ser tomadas en conflictos específicos en cada campo particular" (Couldry 2003, p. 668).

\section{Bernardo: su ascenso como vedette del periodismo político}

Tal como la entendemos aquí, la notoriedad mediática no es equivalente a un golpe de fama, que puede resultar de una repentina exposición mediática, sino que supone la detentación de una posición dominante, construida a lo largo del tiempo y refrendada por los criterios de jerarquización que priman en los espacios mediáticos y en el campo periodístico. Por lo tanto, devenir un periodista notorio supone una constante inversión del "sujeto" sobre sí mismo para acumular recursos, que condensados en su nombre, en su firma y en su imagen puedan, en las condiciones adecuadas, operar como capital simbólico.

La reconstrucción del derrotero profesional de Bernardo Neustadt ${ }^{4}$ permite dar cuenta de cómo las diversas y cambiantes estrategias de ascenso que el periodista emprendió se articulan con los cambios producidos en la esfera mediática desde los años cincuenta hasta los noventa. Para ello, analizamos los
${ }^{4} \mathrm{El}$ presente apartado retoma
y profundiza el análisis sobre el perfil del periodista realizado en Vommaro \& Baldoni (2012). 
vínculos sociales y las posiciones que, a lo largo de su carrera, le permitieron acumular recursos que lo llevaron a convertirse en una figura notoria del periodismo político, en el momento en que las lógicas de la vedettización entraron en escena.

Proveniente de una familia de clase media, que lo había dejado pupilo en un colegio salesiano y con la que había mantenido escaso contacto, Neustadt abandonó sus estudios secundarios e ingresó muy joven al mundo del periodismo. En 1940, con sólo 14 años, se incorporó a la redacción del diario El Mundo como cronista deportivo y, un año más tarde, a la revista Racing, en la que llegó a ocupar el puesto de Secretario de Redacción. Como para muchos de los colegas varones de su generación, la sección Deportes constituía una puerta de entrada de fácil acceso al mundo del periodismo, que podía oficiar luego como puente hacia la más restringida sección Política.

En 1945 Neustadt cruzó ese puente y comenzó a cubrir las noticias parlamentarias del diario. Desde esta nueva función, estrechó vastos vínculos con actores del mundo político, que le permitieron combinar la actividad periodística con la participación en cargos de gobierno. Pronto, se incorporó a la revista $P B T$, de clara filiación peronista. Luego, en 1953, de la mano de Alberto Teisaire, vicepresidente de la Nación durante la segunda presidencia de Juan Domingo Perón, se convirtió en Jefe de Prensa del Consejo Superior Peronista y, a partir de 1954, fue nombrado Director General de las Relaciones con las Organizaciones del Pueblo, en la Secretaría de Asuntos Públicos de la Nación. Asimismo, se desempeñó como Secretario Privado en la Vicepresidencia.

Tras el derrocamiento del gobierno peronista, sus vínculos políticos se volvieron un obstáculo para su carrera periodística. En 1955 fue despedido del diario El Mundo, cuando éste fue confiscado por las autoridades del nuevo gobierno de facto y su dueño acusado de "traición a la patria" (Fernández Díaz 1993). Para salir del ostracismo en el que había caído, inició un proceso de "desperonización” y tendió nuevas redes. En 1957 logró ingresar a la sección política de Clarín, en donde llegó a escribir su propia columna. Allí conoció a Moisés Jacoby, Secretario General del matutino, quien, en 1960, junto a Jacobo Timerman, estuvo a cargo de la renovación del diario El Mundo y volvió a convocar a Neustadt, ahora, como Secretario de Redacción.

Por aquellos años, Neustadt decidió dar un salto cualitativo en su estrategia de inserción en los medios e ingresó al novedoso ámbito televisivo. En 1961 debutó como conductor en un micro denominado "La pregunta de hoy", en el que entrevistaba a un personaje político de primera línea. Luego, co-condujo los programas "Nosotros", "Incomunicados" y "Nunca se contó", un ciclo que reconstruía las biografías de importantes empresarios.

En el momento de mayor esplendor de las revistas políticas, se propuso incursionar en ese ámbito con dos proyectos editoriales. En 1964 fundó la revista Todo y un año más tarde, la revista Extra, la cual mantuvo hasta su cierre en 1989. Sin llegar a tener la trascendencia ni el prestigio de otras publicaciones de la época, como Primera Plana y Confirmado (Ruiz 2001; Ulanovsky 1997), sus revistas, orientadas a las clases dirigentes, constituyeron para el periodista un puente fundamental para entablar vínculos sociales con las clases más favorecidas (Borrelli \& Iturralde 2014), a la vez que representaban un próspero negocio que, a través de la publicidad, le permitía ganar independencia económica.

En 1967, mientras ingresaba al mundo de la radio y cuando la televisión aún no cumplía su segunda década en el país, también inició el ciclo de periodismo político que lo acompañó casi por el resto de su carrera y que se constituyó en su propia marca. Su famoso programa de debate político "Tiempo Nuevo", pio- 
5 Durante la década de 1970 la televisión se vio afectada por los vaivenes políticos. En 1974 fueron estatizados por el tercer gobierno peronista (1973-1976) los canales de aire privados, que posteriormente fueron controlados por las Fuerzas Armadas durante el gobierno de facto (1976-1983). En ese escenario, "Tiempo Nuevo" fue censurado en dos oportunidades. No obstante, los vínculos de Neustadt con las élites políticas y empresariales le permitieron volver a la pantalla.
${ }^{6}$ En 1989, a través de la derogación del art. 45 de la Ley de Radiodifusión, que impedía la propiedad simultánea de medios gráficos $\mathrm{y}$ audiovisuales, Menem promovió una larga serie de privatizaciones de señales televisivas y radiales (Baranchuk 2005). Este cambio legislativo posibilitó la conformación de multimedios y fue el desencadenante del creciente proceso de concentración de la propiedad de medios (Becerra \& Mastrini 2009). nero en el género, se incorporó a la pantalla chica cuando el centro de gravitación del periodismo político se encontraba aún en la prensa gráfica. Sorteando los vaivenes de los convulsionados cambios de regímenes políticos, el programa se mantuvo en el aire durante 30 años de manera casi ininterrumpida ${ }^{5}$. En el ámbito periodístico, se atribuyó este logro en gran parte a la capacidad de aggiornamiento y de negociación de su conductor-productor con las autoridades políticas de turno. En los años ochenta, con la ampliación de la cobertura televisiva (Landi 1992), el programa se convirtió en un éxito, liderando las entonces flamantes mediciones de audiencia. Neustadt junto a su co-conductor, Mariano Grondona, devinieron así en referentes del periodismo político en su formato televisivo.

Para entonces, Neustadt había multiplicado sus espacios de intervención en los medios al punto de convertirse, como lo definió años más tarde uno de sus colegas, en "un multimedios ambulante" (Al final, lo dejaron solo 1997). A la publicación del semanario político Extra, sumó la creación de la revista especializada en economía y negocios Creer (1975-1984), desde la cual estrechó férreos vínculos con el mundo empresario. Desde 1981 se había convertido en el columnista de opinión del diario Ámbito Financiero, cuando éste buscaba desarrollar y darle más protagonismo a su sección política (Ruiz 2005, pp.9293). En radio, también lideraba la audiencia con su programa "Despertando con Bernardo Neustadt", que se transmitía por la mañana en Radio América. En el recientemente creado sistema de televisión por cable, conducía su ciclo semanal "Al estilo de Bernardo Neustadt", en el canal de Cablevisión, la mayor empresa operadora de cable del país.

La fructífera estrategia de multiposicionamiento del periodista fue revalidada por las entonces flamantes instancias consagratorias, que se articulaban en torno a la reconstitución del mundo de la cultura y del espectáculo tras la censura de último gobierno dictatorial (1976-1983). En 1987 fue galardonado con el premio Konex de Platino por su labor periodística televisiva durante la década. Entre 1988 y 1989 recibió tres premios Martín Fierro por el programa “Tiempo Nuevo" y estuvo nominado por su emisión radial.

Cuando, a principios de los años noventa, la creciente masificación y comercialización del espacio mediático se profundizó radicalmente con la privatización y conformación de grandes grupos (Baranchuk 2005; Becerra \& Martini 2009) ${ }^{6}$, Neustadt se encontraba en una posición adelantada para capitalizar su notoriedad mediática y hacer de su público la fuente de su poder. Por un lado, en tanto productor de sus espacios radiales y televisivos, contaba con anunciantes propios a los que presentaba como "las empresas a las que le interesa el país" y, por otro, la participación de personajes de primera línea como invitados de su programa refrendaba su poder de convocatoria y su lugar destacado en el medio, a la vez que propiciaba un círculo virtuoso de mantenimiento y ampliación de su audiencia. En un reportaje titulado con la frase "El público es el único que puede terminar con mi éxito", Neustadt hacía referencia explícita a su notoriedad y a la detentación de esta forma de capital:

En principio somos todos personas hasta que alguien te pone el "lidad" y pasás a ser una personalidad. Hace rato que estoy en este clima que es lo que los norteamericanos llaman la estrella en el periodismo. El motivo de esa presencia constante fue el haber hecho en los dos últimos años dieciséis horas semanales de radio y doce horas semanales de televisión. Escribí para cinco publicaciones y hablé para siete radios del interior. Todo esto hace que uno tenga más audiencia que muchas editoriales juntas. En una noche de "Tiempo Nuevo" yo tengo dos millones de seguidores y diarios importantes de la Argentina necesitan un mes para tenerlos. (El público es el único que puede terminar con mi éxito, 1990; cursivas agregadas) 
En los años siguientes, su notoriedad llegó a su máxima expresión, cuando las revistas de política y actualidad no sólo lo consultaban sobre temas de coyuntura, sino que se encargaban de seguir los pormenores de su vida privada: su divorcio, su casamiento con una modelo bastante menor que él, su estado de salud, su nueva casa en la zona norte de Buenos Aires y sus vacaciones en Punta del Este, el balneario ícono de la cultura menemista (Fair 2013) en el que se codeaban, en aquellos años, las figuras del espectáculo con las de la política.

De este modo, la notoriedad mediática de Neustadt operó como una suerte de moneda de intercambio que actuaba en dos sentidos. Para las empresas de medios el periodista representaba una vedette que aseguraba audiencia y, por lo tanto, un buen caudal de publicidad; mientras que a los actores del campo político y empresarial les permitía acceder de modo directo a un público masivo o bien, en ciertos casos, operar de manera indirecta a través de la difusión que el periodista hacía de las ideas que les eran afines.

\section{IV. “Soy un simplificador”: la construcción de un público propio}

Como señalamos, la constitución de un público "propio" es uno de los pilares del poder de este tipo de figuras. En este apartado, nos concentramos en las estrategias de interpelación que Neustadt puso en juego para captar a su audiencia, y el modo en que éstas se adaptaron y se articularon con las modificaciones de la estructura de medios y con el contexto de crisis económica y política que atravesó a la Argentina a fines de la década del ochenta. En efecto, fue en aquellos años cuando el periodista decidió ampliar su radio de influencia (Vommaro 2008b) y se comenzó a posicionar como un traductor para su público:

Durante muchos años, como hacen varios colegas míos, me dediqué a ver si me leían o escuchaban los de la clase dirigente. Y me escuchaban, el diputado tal me escuchaba. Pero hace cuatro o cinco años que me escucha el colectivero, el taxista, Doña Rosa. En vez de plantear utopías () me dediqué todos los días a un tema al alcance de todos. Y la gente respondió. (El público es el único que puede terminar con mi éxito 1990)

Esta búsqueda de un público masivo resulta congruente con las transformaciones ocurridas en el campo político-periodístico. En efecto, fue recién en aquellos años que, gracias a la generalización de los aparatos de televisión y del sistema de cable (Marino 2012), se conformó una audiencia nacional (Landi 1992). A su vez, con la creciente comercialización del sistema de medios, las mediciones de audiencia devinieron uno de los principales criterios de validación de los programas televisivos y de sus conductores (Vommaro 2008a). Esta primacía de la ley del mayor número, en tanto imperativo del mercado, involucraba también un cambio en la representación política del público. Como sostiene Champagne para el caso francés (1994, pp.12-13), a partir de la difusión de las mediciones de audiencia como una práctica corriente del ambiente televisivo y de la reproducción de estas cifras en la prensa diaria, los televidentes comenzaron a ser considerados como una masa amorfa de consumidores que emiten una suerte de "voto" a través de la elección de los programas. El rating se transformó así no sólo en un desafío económico, sino también en un indicador de legitimidad social; mediante el cual periodistas, políticos y otras figuras públicas "medían" su notoriedad y prestigio y competían por tener la mejor "marca".

La construcción de un público propio involucró, por parte de Neustadt, inversiones y apuestas para orientar sus estrategias de captación a ese interlocutor "virtual", que se encontraba del otro lado de la cámara o del micrófono. Dentro del abanico de posibilidades, no parece casual que el periodista intentase posicionarse como representante de los intereses de aquel sector social que 
consideraba mayoritario, y que englobaba tras la categoría de "clase media". La identificación entre el periodista y su público se cimentaba, principalmente, en una retórica de ascenso social. Según Morin, a mediados del siglo XX, las estrellas del star system se constituyeron, para las emergentes clases medias, en un modelo de la ética de la individualidad y de sus estilos de vida asociados (Morin 1984, p. 66). En este sentido, la constante reafirmación por parte del periodista de un relato biográfico, que contraponía su éxito presente a su pasado plebeyo al estilo del self-made man, se orientaba a la búsqueda de empatía aspiracional con ese público al que pretendía interpelar.

\section{P: Usted dice que representa la opinión pública}

BN: A la clase media concretamente, que es la que está más desprotegida ()

P: ¿Se considera un intérprete de la sociedad?

BN: Sí, de un sector multitudinario. Desde una posición cómoda, que es la de estar sentado sobre el éxito () Yo pasé lo que está pasando la gente, supe lo que es tener hambre, trabajé en un diario por cincuenta centavos por día, supe estar despedido, por todo eso me siento absolutamente consustancial con ellos. Esto es lo que me da cada vez más seguridad de lo que hago. (El público es el único que puede terminar con mi éxito 1990)

“Doña Rosa", el personaje que construyó como su interlocutor predilecto, intentaba así encarnar los atributos de esta clase media a la que el periodista se dirigía. Este giro en la orientación de su estrategia comunicativa hacia el gran público coincide con una coyuntura de profunda crisis económica y política. Mientras que, con la restauración de la democracia en 1983, la palabra política había recuperado su capacidad de interpelación y la política aparecía como el instrumento principal de transformación social, hacia el fin de esa década las crecientes dificultades que encontró el gobierno de Alfonsín para estabilizar este nuevo orden institucional fueron erosionando la legitimidad del discurso político. Por una parte, la abdicación del poder político frente a las demandas de amnistía de la corporación militar, con el dictamen de las llamadas leyes de Punto Final y Obediencia Debida, pusieron en entredicho la legitimidad de un discurso que se había anclado en la defensa de los derechos humanos (Landi 1992; Rinesi \& Vommaro 2007). Por otra, los infructuosos intentos de reactivación económica y el constante crecimiento de la inflación, que se había constituido en una de las principales preocupaciones públicas y que derivó en una crisis hiperinflacionaria sin precedentes en 1989, agudizó el descrédito de los partidos políticos (Pucciarelli 2006; Heredia 2015).

En el marco de esta coyuntura crítica, el discurso antiestatista de Neustadt encontró un ámbito propicio de recepción. En efecto, si bien esta prédica no era nueva en su repertorio, a partir de 1987, tras la pérdida de las elecciones legislativas por parte del partido de gobierno, el periodista centró sus intervenciones en algunos elementos que la crisis dejaba a su disposición. Uno de sus tópicos más recurrentes era la denuncia del deterioro del funcionamiento de los servicios públicos, particularmente el telefónico, como un indicador "evidente" de la ineficiencia del Estado y de la consecuente demanda de privatización. La centralidad que le otorgaba a este tema era tal que, en uno de sus programas, haciendo uso de sus capacidades de simplificación y de los recursos audiovisuales, se dedicó a desarmar un aparato telefónico para demostrar que adentro "no se encontraba la Patria" (Neustadt 1996, p.223). Desde su lectura, en el déficit que generaban las empresas públicas se encontraba la gran causa del "fracaso argentino" y de la "inflación galopante" que afectaba directamente "el bolsillo" de los argentinos y las posibilidades de ascenso social de la clase media, que el periodista decía representar.

Cuando las señoras de la calle me comentan "sabe que usted dijo lo que yo pensaba", a mí me alcanza. Me alcanza con lo que piensa Doña Rosa, que puede 
ser una docente, una abogada, una profesora; puede ser un ama de casa, la propietaria de un comercio, una profesional fracasada porque no tiene empleo y termina trabajando en cualquier cosa. Y yo, cuando me acusan de que simplifico mucho las cosas, digo que tienen razón. Porque los de arriba las complican mucho y yo soy un intermediario entre el que la complicó arriba y la señora que está abajo. Yo soy un simplificador. (Neustadt, en: Soy un simplificador 1990, p. 10 ; cursivas agregadas)

El discurso de Neustadt se nutría y mantenía una estrecha sintonía con los diagnósticos monetaristas de la inflación que, como señala Heredia (2015), habían ganado un fuerte consenso en el ámbito público, gracias a las intervenciones de los economistas ortodoxos. Por consiguiente, la efectividad y la fortaleza de las intervenciones de Neustadt no residen en su originalidad, sino más bien en su papel de traductor de estos saberes expertos, que justamente asentaban su pretendida neutralidad en el manejo de un lenguaje técnico de difícil comprensión para el público lego. Si este diagnóstico, que colocaba al Estado como el gran responsable de la crisis, había logrado permear diferentes esferas sociales (Beltrán 2006; Sidicaro 2001), Neustadt contribuyó a este proceso articulando algunas de las grandes premisas de estos esquemas de pensamiento con la experiencia cotidiana de una población atravesada por una profunda crisis.

\section{Nuevos tiempos: alianzas entre periodistas y políticos}

El ingreso del periodismo político al ámbito televisivo habilitó un nuevo espacio de interacción entre periodistas y políticos. Con la creciente mediatización de la política (Landi 1992; Quevedo 1999; Sarlo 1997), los programas de este género se convirtieron en uno de los escenarios privilegiados de las contiendas públicas. En ellos, políticos profesionales, periodistas y otras personalidades públicas podían establecer alianzas entre los pasajes de los bastidores a la pantalla. A la típica relación del periodista con sus fuentes políticas, que podía mantenerse a reparo del público (Legavre 1992; Schlesinger 1990), ahora la pantalla sumaba un espacio de teatralización de esa relación en la que la audiencia jugaba un papel central. En el caso de los periodistas notorios que, como Neustadt, contaban con un público "propio", esta situación les permitía colocarse como intermediarios entre los dirigentes y su audiencia, la cual, como señalamos, se constituía entonces en una moneda de cambio en las negociaciones e intercambios establecidos con sus invitados.

Los vínculos que Neustadt estableció con distintos dirigentes permiten analizar las relaciones entre periodistas y políticos balo la lógica, denominada por Neveu (2002), de "socios-rivales". Así, aquellos mismos periodistas que, al posicionarse como voceros de la opinión pública, les disputaban a los políticos la legitimidad de su representación social eran quienes también les posibilitaban acceder a un público masivo desde sus espacios mediáticos. En efecto, para los dirigentes, estos espacios constituían un soporte esencial para difundir sus propuestas y un escenario propicio para construir una imagen de cercanía con el electorado por fuera de las arcas partidarias.

“Tiempo Nuevo", el programa que Neustadt conducía junto a su colega Mariano Grondona, se mantuvo como único en su género en la grilla televisiva durante los años ochenta. Ambos periodistas sostuvieron desde el comienzo una postura crítica frente al gobierno de Raúl Alfonsín (1983-1989), que se agudizó hacia el final de su mandato ${ }^{7}$. Con este perfil, "Tiempo Nuevo" devino una arena privilegiada en la que los economistas ortodoxos, provenientes de la Fundación de Investigaciones Económicas Latinoamericanas (FIEL) y del Centro de Estudios Macroeconómicos de la Argentina (CEMA), libraron una "batalla ideológica" contra el entonces ministro de economía, Juan Sourrouille

${ }^{7}$ Los compromisos con distintos sectores vinculados a regímenes dictatoriales que Neustadt y Grondona habían sostenido en el pasado los distanciaban del proyecto de 
reinstauración democrática del gobierno de turno (Sivak 2005). Desde el arco más progresista del periodismo, comprometido con la defensa de los derechos humanos, se les criticaba la falta de objetividad de sus reportajes y editoriales (Baldoni 2010).

${ }^{8}$ Algunos de los artículos periodísticos citados que fueron consultados en el Archivo del diario Página 12 no cuentan con número de página.
(Heredia 2011, p.305). En esos años, el dirigente político Álvaro Alsogaray se convirtió en el principal habitué de la emisión. Desde este lugar en la pantalla, Alsogaray se ocupó de traducir en términos políticos las críticas realizadas por los especialistas al modelo económico y social del ministro Sourrouille que, según él, se encontraba agotado debido a su carácter "dirigista, intervencionista, estadista e inflacionario" (Tiempo Nuevo 1987).

Aunque se conocían desde hace tiempo, la relación de Neustadt con el ingeniero, como llamaban a Alsogaray en los medios, se estrechó cuando Alsogaray decidió fundar, en 1982, el partido Unión del Centro Democrático (UCeDé), de orientación liberal-conservadora, para competir en el terreno político-electoral. Neustadt le abrió un espacio central en su programa para que Alsogaray difundiera a su público sus propuestas de campaña para las elecciones presidenciales de 1989, a las que se postulaba como candidato. Alsogaray no resultó electo, pero luego, en parte gracias a la visibilidad que había alcanzado, se sumó a elenco del gobierno del justicialista Carlos Saúl Menem, que triunfó en las urnas.

Por su parte, la alianza entre Menem y Neustadt, que con altos y bajos se mantuvo durante sus dos gobiernos (1989-1995/1995-1999), se selló también ante el público el martes siguiente a las elecciones de mayo de 1989, cuando el flamante presidente electo acudió a los estudios de "Tiempo Nuevo". Durante la campaña, Menem, quien entonces no era el candidato predilecto de Neustadt, ya había participado del programa como invitado. En una de estas ocasiones, fuera de cámara, el candidato había comenzado a desplegar su estrategia de acercamiento a Neustadt. Así, lo recordaba el periodista:

\begin{abstract}
Mire, muchos meses antes, cuando nos encontrábamos [con Menem] en un programa mi carga de crítica era durísima. En los intervalos, Menem riéndose me decía: "Qué duro es conmigo, Neustadt. Qué injusto. Si lo que usted sugiere yo lo voy a aplicar, si yo voy a poner en práctica lo que usted dice". Yo le decía entonces contestándole con ironía "Usted lo que quiere es sobornarme, ¿Por qué me lo dice entreactos? Yo no creo que usted haga eso". Y él me decía: "Yo lo voy a hacer. No hay otra posibilidad que ir hacia un mundo capitalista de libre competencia". (Soy un simplificador $1990^{8}$; cursivas agregadas)
\end{abstract}

Una semana antes de las elecciones, tuvo lugar en el piso de "Tiempo Nuevo" el frustrado primer debate presidencial en televisión. Esa noche, el candidato peronista no acudió a la cita, y el periodista decidió graficar su ausencia con una pantalla dividida: de un lado, el candidato radical Eduardo Angeloz; del otro, una "silla vacía". No obstante, a la semana siguiente, Menem, ya electo, se presentó en el estudio para darles a los conductores una entrevista exclusiva. Neustadt le agradeció el gesto: "Nosotros, en nombre mío, y yo diría de Grondona y de la sociedad que nos escucha, queremos agradecerle a Carlos Saúl Menem que es el primer presidente electo que yo conozco que va a un canal de televisión" (Tiempo Nuevo 1989). Esta frase celebraba y condensaba, así, el comienzo de un período en el que la mediatización de la política se instalaba éxitosamente. En este sentido, Neustadt solía recordar en las entrevistas que brindaba el establecimiento de este vínculo con el entonces presidente como un logro:

BN: Con el doctor Alfonsín, mientras fue presidente, tomé un té de quince minutos en Olivos () Con Menem pasó algo distinto. Hicimos dos o tres programas previos antes de su triunfo () En uno de los últimos programas antes de la votación Angeloz lo desafió, el famoso episodio en que quedó una silla vacía. Faltaban pocos minutos para el aire, Menem llamó y dijo "Neustadt, dígale al Pocho que por hoy hable con la silla y usted la semana que viene va a hablar con el presidente de la Nación" () Lo cierto es que al martes siguiente, sin invitación previa, Menem, ya presidente, se presentó en los estudios de canal 2 y salió al 
aire una hora. Se fue, yo terminé el programa y al salir él me estaba esperando. Me dice que me quiere conocer, y me invita a comer.

P: Casi como un amor a primera vista.

BN: Algo así. (En comparación, mi autocrítica se va achicando cada día 1992, p. 2 ; cursivas agregadas)

En esta alianza, gestada tras bambalinas y sellada luego en el aire, se entrecruzaban los intereses particulares del político y del periodista. Por un lado, como sostenía un funcionario de gobierno, a Menem le interesaba particularmente la llegada al público de clase media que seguía a Neustadt y al que él no podía acceder desde los bastiones del peronismo (El Mundo Perdido: Bernardo Neustadt, la hora clave de su sombra 1992). Por otro, para el periodista, este acercamiento no sólo le permitía beneficiarse en pantalla de la popularidad de un presidente que accedía a ser su asiduo invitado, sino que además el tipo de relación que Menem entabló con él lo colocaba en una aparente situación de paridad con la clase dirigente. Así, en la mesa de "Tiempo Nuevo", este intercambio de público y de vínculos sociales se articulaba con un sentimiento de reconocimiento y de ascenso en las jerarquías sociales para el periodista y de popularidad para el dirigente.

P: Neustadt, ¿usted le baja línea al presidente?

$\mathrm{BN}$ : Conversamos. Por lo menos dos o tres veces a la semana nos llamamos por teléfono ()

P: ¿Usted había almorzado alguna vez con un presidente?

BN: Nunca. Esta es la primera. Ya me invitó tres veces. Yo no había entrado nunca a Olivos y el último de esos almuerzos fue en Olivos. Y son momentos para discutir. Porque no me llama para que yo diga "hola, amén". Sino para escucharme y tener en cuenta lo que digo ()

P: Hablando de historia, ¿cuándo se conjugaron la suya y la del presidente Menem? Quiero decir, ¿usted escribe a Menem o Menem le escribe a usted?

BN: Yo le contestaría al revés. Usted quiere saber si yo me hice menemista. No, el Presidente es el primer neustadista. Podemos andar por caminos iguales y por senderos distintos. Por ejemplo, la Plaza del Sí es una idea mía que tomó la forma de miles de propuestas. (El Presidente es el primer neustadista 1990; cursivas agregada)

De este modo, como sostiene Rieffel (1989, p.215), es posible advertir que la emergencia de las vedettes periodísticas "favorece notablemente una suerte de comunidad de intereses entre actores antes distanciados por sus estatus o sus funciones", en particular cuando, debido a las transformaciones en la comunicación política, la mediatización deviene un imperativo para los dirigentes políticos. Asimismo, estas alianzas entre políticos y periodistas refleja como la creciente dependencia de audiencias a las que sólo se alcanza a través de los medios puede tornar imperativo el acceso a estos espacios para actores de campos no mediáticos (Couldry 2003, p.663).

\section{La Plaza de Bernardo}

En 1990, tras el éxito en las urnas, el gobierno de Menem se encontró con serias dificultades para rearmar su proyecto de gestión y reconvertir su legitimidad electoral en legitimidad de ejercicio. Por una parte, el fracaso de los intentos gubernamentales parar estabilizar la economía tras la crisis hiperinflacionaria que dio lugar al traspaso anticipado de la presidencia en julio de 1989 debilitó el apoyo social que el gobierno, y especialmente la figura presidencial, habían obtenido unos meses antes (Palermo \& Novaro 1996; Pucciarelli 2011). Por otra parte, su programa neoliberal de reforma del Estado y de privatiza- 
9 Si hasta entonces los medios se habían ocupado de dar cobertura a la política, era ahora la política quien iba hacia los medios y entraba en escena, con la asidua participación de la principal figura institucional en los distintos platós televisivos (Cheresky 2002; Landi 1991; Quevedo 1992). ciones de empresas públicas encontró una fuerte resistencia por parte de los gremios estatales y del arco político opositor, que por entonces se había ampliado y comprendía a importantes sectores del partido justicialista, los cuales veían en el modelo propuesto por el presidente una traición a la identidad peronista y a los intereses de su base social.

Signado por recurrentes paros y huelgas, este escenario conflictivo se trasladó a la calle a través de la primera manifestación contestataria, organizada el 21 de marzo de 1990 frente al Congreso, por el líder sindical Saúl Ubaldini. En ella, los manifestantes reclamaron para sí el legado peronista y denunciaron el carácter "espurio" de las alianzas que el gobierno había establecido con sectores de la derecha liberal, como la UCeDé de Alsogaray. El relativo éxito de la marcha, en la que participaron entre 35.000 y 60.000 personas, planteaba nuevos desafíos para la infructuosa estrategia de rearmado de poder menemista.

La Plaza del Sí, como su nombre lo indica, fue concebida como una clara respuesta a la "Marcha del No" de los gremios: su consigna principal era el apoyo al rumbo económico y social elegido por el gobierno. El inesperado y rotundo éxito que tuvo la convocatoria condensó y le dio entidad pública a la nueva coalición de fuerzas sociales, donde participaban actores extrapartidarios y en la cual se asentó el rearmado de la estructura de poder del menemismo (Pucciarelli 2011). Como señalan distintos estudios (Etchemendy 2016; Gervasoni 1998; Gibson y Calvo 2000), la reestructuración del poder que emprendió el gobierno de Menem también involucró alianzas y coaliciones con diversas organizaciones y actores políticos institucionales. Sin embargo, interesa aquí remarcar el modo en que las alianzas emprendidas por el presidente con actores extrapartidarios, en particular aquellos pertenecientes a los medios, operaron como una estrategia de legitimación pública y de búsqueda de popularidad, que contribuyó a transformar las lógicas de la comunicación política9 .

El impacto simbólico de la Plaza del Sí, por lo tanto, no sólo se vincula con la masividad que alcanzó el acto, sino, particularmente, con sus características inéditas. Uno de los trazos distintivos de esta manifestación pública se encuentra en la centralidad que figuras de los medios de comunicación tuvieron en la convocatoria, no sólo como transmisores del mensaje, sino como activos promotores. Aunque internamente disputada, la paternidad de la idea fue atribuida a Neustadt.

Dos días después de la manifestación de los gremios estatales, en su columna semanal de opinión en el diario Ámbito Financiero, el periodista se ocupó de criticar la metodología de protesta de Ubaldini. Asimismo, aprovechó la oportunidad para responder a la acusación que el dirigente había vertido en el discurso del acto, al señalar irónicamente que Alsogaray era un "cliente" de Neustadt. La crítica a los paros, las huelgas y las protestas callejeras de los gremios no era una novedad en la galería de temas tratados por Neustadt; sin embargo, en esta ocasión, se asomaba una propuesta novedosa. El mismo periodista que constantemente le negaba representación social a los manifestantes que solían ocupar la calle ahora proponía disputar ese mismo espacio y llamaba a su público a marchar a Plaza de Mayo por el "sí".

Lo felicito por el acto en orden y por reunir 25.000 u 80.000 fervorosos. Le recuerdo que más de 30 millones de argentinos no fueron... Siguieron trabajando. ¿Serán los que no piensan como usted? ¿No sería interesante averiguarlo?

Saúl: hace años que usted es el dueño del "no". Con su permiso voy a tratar de llenar una plaza, como a usted le gusta, con argentinos que digan "sî".

¿Le molesta? (Neustadt, en: Saúl 'querido' (dueño del 'no’) 1990, p.12)

Ese mismo día, el 23 de marzo de 1990, la agrupación política "Menem Conducción" le alcanzó la propuesta al presidente. Luego, el dirigente sindical 
oficialista Luis Barrionuevo anunció públicamente la realización del acto para el 6 de abril (Qué hay en la trastienda 1990, p.4). Pese al papel jugado por las instituciones políticas y gubernamentales en la convocatoria y en la organización del evento, la apelación apolítica que tiñó su difusión buscó obturar estos rastros de organicidad (Pucciarelli 2011). Así, cuando, unos días antes del evento, la UCeDé decidió adherir orgánicamente a la marcha, forzando a Menem a solicitar el apoyo del Partido Justicialista; el presidente les demandó a sus militantes y simpatizantes que marcharan sin las tradicionales banderas e insignias partidarias.

En el ámbito mediático, dos figuras conformaron, junto a Neustadt, la alianza en la que se sustentó buena parte de la convocatoria. Por un lado, se encontraba el empresario Constancio Vigil, propietario de la Editorial Atlántida, quien, gracias a las privatizaciones de medios ya emprendidas por Menem, había adquirido el Canal 11 de televisión (Baranchuk 2005), al que sumó luego Radio Continental. El grupo contaba también con un conjunto de publicaciones gráficas, entre las que se destacaban la revista política Somos (1976-1993) y la revista de sociedad Gente (desde 1965). Por otro lado, de esta alianza también participó el conductor y productor televisivo Gerardo Sofovich, quien había sido designado por el gobierno como coordinador de la privatización del zoológico de Buenos Aires y más adelante nombrado interventor de la señal de televisión pública Argentina Televisora Color (ATC).

Junto a ellos, Neustadt se convirtió en el gran promotor público del acto, al activar una intensa y masiva campaña para movilizar a sus seguidores desde sus propios espacios mediáticos y los de sus aliados. Al mismo tiempo, los organizadores "oficiales" de la marcha se encargaron de difundir el llamado con afiches sin firma en la vía pública y con solicitadas firmadas por figuras del deporte, de la cultura y del espectáculo, en los principales diarios del país. Bajo el lema "Los que queremos el cambio" y "La gente convoca a la gente", las solicitadas que se presentaban como absolutamente "inorgánicas" retomaban buena parte de la retórica apartidaria vertida en las intervenciones del periodista y de otras figuras de los medios.

Para interpelar a su audiencia a movilizarse a la Plaza del Sí, Neustadt puso a jugar sus habilidades comunicativas y reelaboró una serie de etiquetas políticas y sociales, que le permitían condensar el sentido de su apelación. Así, esta se dirigía a un conjunto social particular, que él nominaba los "socios del silencio":

${ }^{10}$ La apelación a la "mayoría silenciosa", referida a un conjunto de ciudadanos que no expresan su opinión, ganó relevancia con su recurrente utilización, a partir de 1969 , por parte de Richard Nixon, con el objeto de avalar la Guerra de Vietnam. En su análisis del caso, King y Anderson (2009) muestran cómo el término se inscribió en una retórica de la polarización, que el presidente estadounidense utilizó como una estrategia política de legitimación. se trataba de los ciudadanos - la "mayoría silenciosa"10 - que deseaban las privatizaciones, pero que se habían mantenido hasta ese momento como "espectadores", mientras las minorías que "aullaban" ocupaban las calles, condenándolos a ser "ciudadanos de quinta". Frente a esas minorías, mediante las cuales Neustadt hacía referencia a los gremios estatales y a sus dirigentes y a los que no dudaba en llamar "los dueños del fracaso", debía hacerse ahora presente la "fuerza de las mayorías", a las que él llamaba a participar y que conformaban su público. De hecho, erogándose su representación, durante la convocatoria el periodista buscó diferenciar su llamado a los "socios del silencio" -que no se expresaban y que, por tanto, debían ser hablados por él- del llamado que realizaba la dirigencia oficialista a otros sectores sociales: $s u$ plaza era otra.

No tengo nada que ver con la convocatoria a la Plaza de Mayo de los gremios y dirigentes menemistas. Mi "plaza del sî" es otra cosa, es un grito a los socios del silencio para que no sigan de espectadores. Que sean protagonistas. Que no permitan que minorías que aúllan tenga "la calle ganada", mientras que los argentinos que trabajan y sueñan ven pasar la historia desde una resignación exasperante. No nos van a ganar los dueños del fracaso. Hay que hacerles notar que los socios del silencio son más. Que el "no" es un curro excepcional. (Neustadt, en: Cadena de la infelicidad 1990, p.14; cursivas agregadas). 
${ }^{11}$ El proceso denominado "crisis de representación partidaria" trasvasa las fronteras nacionales y refiere al debilitamiento del sistema político anclado en la lógica partidaria (Touraine 1995) y a la mutación de una democracia de partidos hacia una "democracia del público" en la que la representación adquiere un formato personalizado y mediado por los medios de comunicación (Manin 1992).

${ }_{12}$ Para el caso argentino, los estudios coinciden en señalar el debilitamiento, durante los años noventa, del lazo representativo que unía a electores y partidos. Este debilitamiento se expresó en la erosión de pertenencias e identidades políticas estables en un sector del electorado no peronista que comenzó a ser identificado como "independiente" y cuyo voto se tornó volátil (Cheresy 2006; García Delgado 1998; Gargarella 1997; Novaro 1994; Torre 2003).
La heterogeneidad de la composición social de los manifestantes, que no se correspondía, según los analistas políticos de los principales medios de prensa, con la tradicional base social del peronismo, le permitía a Neustadt sostener la hipótesis de que su público era el que había entrado en escena. En efecto, al día siguiente, los matutinos, que hablaban de la constitución de una "nueva fuerza política", destacaban el papel de los "espontáneos", en su mayor parte de clase media, que llegaron por sus propios medios desde sus lugares de trabajo. La prensa identificaba en ellos la expresión de una novedosa "opinión independiente", que ingresaba airosa a la arena política. Colocados como contrapunto de los sectores movilizados a través de lógicas políticas clientelares, a partir de una suerte de lectura moral sobre la protesta social que comenzaba a permear los discursos político-periodísticos (Vommaro 2008b), estos sectores individualizados y desvinculados de ataduras orgánicas se amalgamaban así con esta nueva representación política del público.

En el marco de la incipiente crisis de representación partidaria ${ }^{11}$, el socavamiento del lazo entre representantes y representados comenzaba a expresarse en los lenguajes mediáticos, a través de la concepción de la "clase política" como una especie de estamento social separado de "la gente" (Rinesi \& Vommaro 2007; Vommaro 2008a) ${ }^{12}$. Neustadt, como lo hicieron otros colegas en los próximos años, logró situarse como un vocero de la opinión pública. El periodista encontró así, en esta coyuntura, la posibilidad de movilizar a su público a un acto político a través de un discurso cuya eficacia residía, precisamente, en su efecto de "despolitización".

En términos del efecto de "despolitización”, la misma lógica de la convocatoria estuvo desde el comienzo atravesada por este juego de legitimación/deslegitimación de las formas de participación política: la Plaza debía llenarse para luego ser vaciada de su poder simbólico como fuente de legitimidad política. La nota sobre el acto del diario Ámbito Financiero, titulada "Fue un éxito. Punto", graficaba con claridad esta proyección, que encontraba en todo reclamo obrero y manifestación organizada una expresión del corporativismo de la "vieja política" y llamaba al abandono de este tipo de prácticas (Fue un éxito. Punto 1990).

En línea con las concepciones que condenaban este tipo de protesta social, tras el éxito de la Plaza del Sí, Neustadt, que había llamado a su público a movilizarse y convertirse en protagonista, lo invitaba ahora a ocupar su lugar "natural": el de espectador frente a la pantalla. Para ello, le ofrecía un nuevo menú televisivo. Al igual de lo que hicieron las nóveles emisiones periodísticas que comenzaban a competir con el programa, en "Tiempo Nuevo" las problemáticas sociales, que pudieran interesarle a un público amplio "distanciado" de la política, ganaron cada vez mayor protagonismo en detrimento de los temas e invitados típicamente políticos.

\section{El declive: reconfiguraciones del campo periodístico}

Atónitos por el éxito que había tenido la convocatoria por el "sî", en los días sucesivos, los medios centraron su mirada sobre el periodista que se había convertido en su principal patrocinador público. Aunque con tónicas distintas, que iban desde la reivindicación a la crítica acérrima, las principales publicaciones de la prensa gráfica no pudieron evitar referirse a su figura. Las revistas más cercanas al periodista, pertenecientes a la Editorial Atlántida, le dedicaron al evento y a su promotor la tapa y las principales notas de sus números. En el semanario Somos del 18 de abril, bajo el título "El efecto Neustadt", distintos especialistas fueron convocados para "medir", a través de encuestas, la influencia del periodista sobre los manifestantes en su decisión de participar de la movilización. Las encuestas que, en ese entonces comenzaban a operar como un 
medio de auscultación de la efímera opinión pública (Vommaro 2008a), operaban allí como un dispositivo de legitimación del carácter representativo del periodista. Para alguien que había desarrollado su carrera profesional en gran parte gracias a una continua exposición mediática la Plaza del Sí aparecía como la apoteosis de su notoriedad.

Creo que es la eclosión de una vida profesional. Cuando tenía 13 años fui al diario El Mundo y dije "Voy a ser... quiero ser un gran periodista, quiero tener influencia". El otro día en la plaza, me dije: "Ya está, acá terminó, ya cumplí mi rol, ya puedo de algún modo convocar gente a una plaza que no es mía, tengo influencia en la sociedad. ¿No será el final?”. (Neustadt, en: El efecto Neustadt 1990)

Sin embargo, la interrogación que cierra la cita no es casual ni retórica. La pregunta por el posible final de su carrera que se hace el periodista introduce una problemática fundamental: la de las fronteras de su práctica profesional. Si la Plaza del Sí ponía en evidencia, como analizamos, el poder de convocatoria y de construcción de consensos sociales que comenzaban a detentar por aquellos años las figuras notorias del periodismo; las reacciones que este evento suscitó y el declive posterior de la figura de Neustadt nos permiten ahondar en las reconfiguraciones del periodismo que acompañaron este proceso. En efecto, la intervención directa de Neustadt en la arena política aparecía, a los ojos de sus pares, como una transgresión a los límites de su campo profesional que podía dar lugar a cuestionamientos sobre su condición de periodista. Por ello, si bien Neustadt aceptaba todo comentario laudatorio sobre su papel en el evento, trataba, al mismo tiempo, de demarcarse y de situar su accionar en el contexto de una situación de excepción.

P: Después de la plaza, ¿qué?

BN: () ¿Para mí? Nada. Yo ya terminé. No soy organizador de las plazas ni me gustan las manifestaciones. Esto lo lancé un día del hartazgo que tengo...

P: Parecía un dirigente político... exitoso.

BN: No, mire, lo voy a contrariar (...) No tengo vocación política y esto lo descubrí en la plaza: cuando la gente se abalanzaba, me acariciaba, me besaba y me decía "no afloje", yo sentía entre timidez y vergüenza porque ése no es mi rol. Me dio la sensación de que me había escapado de una misión específica que empecé hace 52 años. Me sentí aturdido, y lo único que ansiaba era que terminara esa manifestación. No vibro con eso ()

\section{P: ¿Usted está proponiendo una nueva forma de representación política?}

BN: Lo que hay que cambiar son los partidos. Hay que cambiar la forma de elegir a los candidatos... Tienen que llegar los mejores, no los que manejan una clientela electoral chiquita... Y es por esto que los comunicadores tienen más suerte que los políticos. Yo soy elegido todos los días y a los diputados los eligen cada seis años. A mí me gusta más así. Desafío a cualquier político -aún con notoriedad-a ver quién puede provocar más a la gente, quién llega más a la gente. Con todo respeto. Y esa no es mi misión: el estado de emergencia me llevó a eso (El efecto Neustadt 1990; cursivas agregadas).

Que los periodistas políticos participen en la producción de bienes políticos y que, por ende, formen parte del campo político no resulta un fenómeno novedoso ${ }^{13}$. No obstante, al colocarse como promotor de un acto que tenía como objetivo explícito apoyar al gobierno de turno, Neustadt emergía en esta coyuntura como una suerte de "operador oficialista", que había -según él, llevado por la "situación de emergencia"- traspasado el límite de su rol profesional y actuado como un político. $\mathrm{Si}$, en principio, esta posición de cercanía con el gobierno no le quitó el apoyo de su público, a medida que en el campo periodístico se instalaba una posición de distancia frente a las instituciones 
${ }^{14}$ Para un estudio pormenorizado de la trayectoria profesional de Mariano Grondona, ver Sivak (2005). Un contrapunto entre el perfil de este periodista y el de Bernardo Neustadt en esta coyuntura se encuentra en Vommaro (2008b) y en Vommaro \& Baldoni (2012).

\footnotetext{
${ }^{15}$ Según una encuesta realizada a 115 periodistas en 1999 por la Facultad de Periodismo de la Universidad de Belgrano, Mariano Grondona figuraba en tercer lugar dentro de los periodistas considerados "más creíbles", mientras que su ex compañero de ruta, Bernardo Neustadt, ocupaba el mismo lugar, pero
}

políticas como modelo deontológico dominante, la relación con sus colegas se tornó cada vez más problemática.

Durante los años noventa, el periodismo de investigación se extendió hasta convertirse en un tipo de estilo periodístico vinculado a la denuncia de actos de corrupción del gobierno (Pereyra 2013). Asimismo, este ideario resultaba congruente con las lógicas comerciales que comenzaban a primar en los canales y emisoras de radio privados, que encontraban en los criterios de "objetividad" e "independencia" periodística una forma de apuntar a un público masivo no diferenciado por tendencias políticas (Muraro 1997). A su vez, los escándalos de corrupción, en general destapados por la prensa gráfica, generaban noticias de alto impacto, que le permitían a los medios audiovisuales una reproducción a bajo costo. Así, por la confluencia de distintos factores, en el campo periodístico, la figura del periodista "independiente" se tornó cada vez más dominante (Vommaro 2008b). Ante este escenario, Neustadt quedó paulatinamente cada vez más fuera de juego, hasta llegar a ser considerado por algunos de sus colegas como una especie de contrafigura.

En 1990, Neustadt sufrió un primer golpe con el alejamiento de Mariano Grondona de "Tiempo Nuevo". Cuando Menem se convirtió en un habitué del ciclo, Grondona decidió diferenciarse de la posición que había tomado su colega respecto al mandatario y abandonó el ciclo para realizar en Canal 9 su propio programa. Desde este nuevo espacio televisivo, llamado "Hora Clave", el periodista buscó darle un giro a su perfil profesional ${ }^{14}$. Por un lado, luego de realizar un mea culpa por sus compromisos políticos pretéritos, que lo vinculaban a sectores golpistas, Grondona asumió como propios los valores democráticos y se distanció del gobierno; giro que el periodista resumía en el slogan de su nuevo programa, "lejos del poder, cerca de la gente" (Sivak 2005, pp.245-252). Por otro lado, el programa le dio lugar a los dirigentes que no eran invitados a "Tiempo Nuevo" o bien que siempre se habían negado a asistir por las posiciones ideológicas que el programa sostenía. En poco tiempo, la estrategia de distinción del periodista rindió sus frutos y "Hora Clave" se convirtió en el programa político más visto de la televisión y Grondona en el periodista estrella del momento.

En una nota titulada "Neustadt vs Grondona. La guerra de los roces" (1992) se mostraba la evolución de los ratings comparados de los respectivos programas de los periodistas entre abril y mayo de 1992. Si, por ejemplo, en la primera semana de abril, "Tiempo Nuevo" había sobrepasado ampliamente en audiencia a "Hora Clave", con 14,5 puntos frente a 6,9, en los programas siguientes esa tendencia se revirtió significativamente. En efecto, en la última semana de mayo, el programa de Neustadt se ubicaba muy por debajo del de Grondona, 10,6 frente a 22,3 .

En el ámbito mediático, el éxito de Grondona era leído como la contracara del comienzo de la decadencia de Neustadt, que, si bien mantenía aún un caudal significativo de público, había sido desplazado del primer lugar del podio en las mediciones de audiencia y en las encuestas de credibilidad, que comenzaban a realizarse cada vez con mayor asiduidad para "medir" las posiciones de los periodistas notorios ${ }^{15}$. Para revertir esa situación, Neustadt matizó su apoyo a la figura presidencial. Primero, lo hizo tratando de sumarse a la retórica de las denuncias de corrupción, a través de la campaña "no roben más" que, fiel a su estilo, promovió de manera incesante por todos sus espacios mediáticos. Con ese ímpetu, retomó y difundió algunas de las denuncias de corrupción que por entonces circulaban en los medios gráficos y se adjudicó el descabezamiento de algunas carteras ministeriales. No obstante, su apoyo al modelo -como él lo llamaba- seguía intacto, y su estrecho vínculo con Menem, tras estos breves desencuentros, se reconstituyó rápidamente. 
entre los periodistas considerados "menos creíbles" (Majul 1999, p.30-35)
En octubre de 1993, una emisión de "Tiempo Nuevo" ofició de testigo del punto en que la figura presidencial y la del periodista se habían fundido. Neustadt, quien ya no buscaba disimular su simpatía por el mandatario y asumía sin más su carácter de periodista oficialista, cedió la conducción de su programa a Menem. El periodista había sufrido un problema de salud por el que tuvo que ser intervenido quirúrgicamente. Ese día, en vez de cancelar el programa, decidió cederle el mando a su invitado principal e intervenir esporádicamente desde su habitación en el Hospital Alemán. Aunque, hacia el final de la emisión, Neustadt trató de demarcar los límites de la negociación de esa escena recordándole a Menem que esa "era su casa", ese intercambio de roles quebraba las reglas de juego de un periodismo que cada vez más se posicionaba como contralor del poder político.

En este episodio, la transgresión de las reglas deontológicas y del tipo de perfil periodístico que empezaba a consolidarse se tornó tan evidente que el entonces columnista del ciclo, Joaquín Morales Solá, abandonó el piso y se alejó definitivamente del programa, afirmando que "no podía aceptarse tan fácilmente un cambio de roles en la sociedad" (El día en que Menem asumió la conducción 1993). En una entrevista posterior, Morales Solá daba cuenta de las razones que lo llevaron a tomar tal decisión, las cuales expresaban con claridad una estrategia de distinción profesional respecto a la posición de Neustadt:

Me negué a participar de esa emisión porque quise preservar mi profesión y algunos valores en los creo () Lo que creo es que el presidente tiene que ser presidente en todo momento y los periodistas debemos ser periodistas en todo momento () Por una razón de coherencia, a partir de aquel martes decidí dejar de ser columnista de "Tiempo Nuevo" (Joaquín Morales Solá, en Archivo de Página 12, s/t, 1993; cursivas agregadas)

Así, a medida que estos roles se cristalizaban, el periodismo "oficialista" que practicaba Neustadt no sólo se volvía anacrónico, sino que despertaba clasificaciones críticas por parte de aquellos que buscaban colocarse en el otro costal a través de estrategias de diferenciación.

El periodista, que como vimos había operado como una especie de bisagra en el salto del periodismo político del papel a la pantalla, se constituía ahora en una contrafigura, particularmente cuestionada por aquellos periodistas que comenzaban a disputarle su posición. Así, por ejemplo, Magdalena Ruíz Guiñazú, una periodista con una larga trayectoria y que experimentaba en esos años un importante ascenso, no perdía ocasión en señalar que "un océano filosófico" la separaba de su colega, a quien definía más como un empresario o como un apologista del poder que como periodista (Magdalena contra los periodistas obsecuentes 1992). En línea con estos idearios, otros periodistas coincidirían en que sus vínculos con el poder político colocaban a Neustadt, en cierto modo, por fuera del campo periodístico.

Unos [periodistas] han sido influyentes desde la independencia, otros desde su cercanía con el poder. No todas las influencias han sido buenas ¿no? () Los periodistas que son influyentes desde el poder, uno podría decir que pierden la calidad de tal. Para mi gusto se transforman. Cuando influís desde el poder () y eso fue lo que le pasó a Neustadt, ¿no? () Eso es algo a lo cual yo me he negado siempre. Cuando vos sos tan influyente y te creés parte del poder, el poder te copta. Entonces ahí dejás de ser periodista y eso le pasó a Neustadt. (periodista político, entrevista con la autora, 19.Feb.2015)

Estos cuestionamientos se enmarcaban, a su vez, en la conformación de un escenario de creciente competencia para el periodismo político televisivo. La privatización de los canales de aire, primero, y la aparición de canales informativos en el sistema de cable, luego, ampliaron notablemente el espectro de programas políticos que debían, ahora, competir entre sí por la audiencia. A su vez, la creación de grupos multimedios, que contenían en su seno publicaciones 
de prensa gráfica y señales audiovisuales, facilitó el pasaje de periodistas desde las redacciones a la arena televisiva y radial. En especial aquellos periodistas que ya contaban con algún grado de experiencia y de reconocimiento en su campo profesional pugnaban ahora por granjearse un nombre en estos espacios masivos. Para estos nuevos periodistas notorios, distanciarse de la figura de Neustadt era también una posibilidad para constituir una identidad propia, disputarle su posición y, a su vez, enmarcarse en posiciones más legítimas, vinculadas a la retórica de la independencia y la autonomía profesional.

P: ¿Quiénes son sus amigos en la política, en el empresariado, en los medios?

BN: No sé. Pero me doy cuenta que separarse, distanciarse, diferenciarse de mí es un negocio. Debe ser porque soy ¿cómo le decía usted?

P: Un modelo.

BN: Eso. Entonces, para llegar a ser igual o parecido al modelo desde abajo hay que ladrarle al que está arriba. Tal vez sea la manera de quedarse con el otro público. Hay políticos que jamás quisieron ir a mi programa y eso me parece muy respetable () Y es así, todos quieren diferenciarse y también quieren blanquearse." (En comparación, mi autocrítica se va achicando cada día 1992, p.2)

En este contexto, junto a la erosión de la popularidad de su principal socio político, Neustadt perdió uno de los principales recursos de su notoriedad: su público. Luego de permanecer treinta años en el aire, "Tiempo Nuevo" llegó a su fin en 1997 debido a sus bajas mediciones de rating. En los años siguientes, tras algunos intentos infructuosos de volver a la televisión de aire, el periodista siguió ejerciendo su oficio en programas de radio y canales de cable de escasa repercusión. Con todo, en 2006, ya casi retirado de la escena mediática, Neustadt intentó volver a pisar la arena pública. De la mano de un grupo de jóvenes, convocó a una marcha contra el gobierno y "a favor de la Constitución". La manifestación no llegó a cubrir las expectativas de sus organizadores y de las 5.000 personas que se esperaban se acercaron, apenas, unas 500. Pese a la escasa trascendencia que tuvo la marcha, que fue irónicamente rebautizada como "la Plaza del Ni" (Bernardo Neustadt. La Plaza del Ni 2006, p.29), Neustadt logró que el entonces presidente, Néstor Kirchner, lo nombrara e hiciera una referencia crítica hacia su persona y, de este modo, como diría el periodista en una carta abierta que le envió al mandatario, lo "salvara del olvido" (Fustigó Kirchner a quienes le critican superpoderes 2006, p.13).

IMicaela Baldoni (micaelabaldoni@gmail.com) es Doctoranda en Sociología en la École des Hautes Études en Sciences Sociales, Francia, y en Ciencias Sociales en la Universidad Nacional General Sarmiento, Argentina. Licenciada en Sociología, investigadora del Instituto de Investigaciones Gino Germani y profesora de la Facultad de Ciencias Sociales de la Universidad de Buenos Aires.

\section{Referencias bibliográficas}

Baldoni, M., 2010. Las transformaciones de los medios de comunicación y el periodismo político durante la década del ochenta y del noventa en Argentina: un recorrido por las trayectorias profesionales de Jorge Lanata y Luis Majul. In VI Jornadas de Sociología de la Universidad Nacional de La Plata. La Plata.

Baranchuk, M., 2005. Canal 11 y 13: la primera privatización de la década menemista. In G. Mastrini. Mucho ruido, pocas leyes. Buenos Aires: La Crujía, pp.215-238.

Becerra, M., \& Mastrini, G., 2009. Los dueños de la palabra: acceso, estructura y concentración de los medios en la América latina del siglo XXI Buenos Aires: Prometeo.

Beltrán, G., 2006. Acción empresaria e ideología. La génesis de las reformas estructurales. In A. Pucciarelli. Los años de Alfonsín ¿El poder de la democracia o la democracia del poder?. Buenos Aires: Siglo XXI, pp.199-243.

Borrelli, M. \& Iturralde, M., 2014. Desde la «zona de confianza» de la dictadura: la revista Extra y la «lucha antisubversiva» (1976-1978). Intersecciones en Comunicación, 8, pp.119-136.

Bourdieu, P., 1979. Les trois états du capital culturel. Actes de la recherche en sciences sociales, 30(1), pp.3-6. 
Bourdieu, P., 1981. La représentation politique [Éléments pour une théorie du champ politique]. Actes de la recherche en sciences sociales, 36(1), pp.3-24.

Couldry, N., 2003. Media meta-capital: Extending the range of Bourdieu's field theory. Theory and Society, 32(5-6), pp.653-677.

Champagne, P., 1994. La loi des grands nombres: Mesure de l'audience et représentation politique du public. Actes de la recherche en sciences sociales, 101(1), pp.10-22.

Champagne, P., 2002. Hacer la opinión. El nuevo juego político La Paz: Plural Editores.

Champagne, P., 2007. L'étude des médias et l'apport de la notion de champ. In E. Pinto. Pour une analyse critique des médias. Le débat public en danger. Paris: Croquant, pp.39-53.

Cheresky, I., 2002. La política, de la tribuna a la pantalla. Designis. La comunicación política. Transformaciones del espacio público, 2, pp.247-258.

Cheresky, I., 2006. La política dspués de los partidos Buenos Aires: Prometeo.

Driessens, O., 2013. Celebrity capital: redefining celebrity using field theory. Theory and Society, 42(5), pp.543-560.

Dyer, R., 2007 [1979]. Stars Londres: BFI.

Esquenazi, J.P., 2009. Du star system au people. Communication. Information médias théories pratiques, 27(1), pp.37-53.

Etchemendy, S., 2016. La economía política del neoliberalismo: empresarios y trabajadores en América Latina, España y Portugal Buenos Aires: Eudeba.

Evans, J., 2005. Celebrity, media and history. In J. Evans \& D. Hesmondhagh (Eds.). Understanding media: inside celebrity. Opne University Press, pp.12-55.

Fair, H., 2013. La construcción y legitimación sociocultural de la hegemonía menemista. Discurso de sentido común y eficacia interpelativa dialéctica. Utopía y praxis latinoamericana, 18(62).

Fernández Díaz, J., 1993. Bernardo Neustadt. El hombre que se invento a si mismo Buenos Aires: Sudamericana.

García Delgado, D., 1998. Crisis de representación, nueva ciudadanía y fragmentación en la democracia argentina. In Gaveglio, S. y Manero, E. (Comps.). Desarrollos de la teoría política contemporánea. Rosario: Homo-Sapiens, , pp.117-144.

Gargarella, R., 1997. Crisis de la representación política Buenos Aires: Fontamara.

Gervasoni, C., 1998. Del distribucionismo al neoliberalismo: los cambios en la coalición electoral peronista durante el gobierno de Menem. In International Congress of Latin American Studies Association (LASA). Chicago.

Gibson, E. L. \& Calvo, E., 2000. Federalism and low-maintenance constituencies: Territorial dimensions of economic reform in Argentina. Studies in Comparative International Development, 35(3), pp.32-55.

Heredia, M., 2011. Los centros privados de expertise en economía: génesis, dinámica y continuidad de un nuevo actor político en la Argentina. In S. Morresi \& G. Vommaro. Saber lo que se hace. Expertos y política en Argentina. Buenos Aires: Prometeo-UNGS, pp.297-337.

Heredia, M., 2015. Cuando los economistas alcanzaron el poder: (o cómo se gestó la confianza en los expertos) Buenos Aires: Siglo XXI.

King, A. A. \& Anderson, F. D., 1971. Nixon, Agnew, and the «silent majority»: A case study in the rhetoric of polarization. Western Speech, 35(4), pp.243-255.

Landi, O., 1991. Videopolítica y cultura. Diálogos de la comunicación, (29).

Landi, O., 1992. Devórame otra vez: qué hizo la televisión con la gente, qué hace la gente con la televisión Buenos Aires: Planeta.

Legavre, J.B., 1992. Off the record. Mode d'emploi d'un instrument de coordination. Politix, 5(19), pp.135-158.

Le Grignou, B. \& Neveu, E., 2017. Sociologie de la télévision París: La Découverte.

Majul, L., 1999. Periodistas. Qué piensan y qué hacen los que deciden en los medios Buenos Aires: Sudamericana.

Manin, B., 1992. Metamorfosis de la representación. In M.R. dos Santos (Ed.). ¿Qué queda de la representación política?. Caracas: CLACSO, Nueva Sociedad.

Marino, S., 2012. Políticas de comunicación en el sector audiovisual: las paradojas de modelos divergentes con resultados congruentes. Los casos de la Televisión por Cable y el Cine en Argentina entre 1989 y 2007. Tesis de doctorado. Buenos Aires: Facultad de Ciencias Sociales, Universidad de Buenos Aires.

Morin, E., 1984 [1957]. Les stars París: Galilée.

Muraro, H., 1997. Políticos, periodistas y ciudadanos: de la videopolítica al periodismo de investigación Buenos Aires: Fondo de Cultura Económica.

Neustadt, B., 1996. No me dejen solo Buenos Aires: Planeta.

Neveu, É., 2002. Quatre configurations du journalisme politique. In R. Rieffel \& T. Watine (Eds.). Les mutations de journalisme en France au Québec. París: Panthéon-Assas, pp. 251-276.

Novaro, M., 1994. Pilotos de tormentas: crisis de representación y personalización de la política en Argentina, 1989-1993 Buenos Aires: Letra Buena.

Offerlé, M., 1987. Les partis politiques París: Presses Universitaires de France.

Palermo, V. \& Novaro, M., 1996. Política y poder en el gobierno de Menem Buenos Aires: Norma.

Pasquier, D. \& Tsikounas, M., 2015. Présentation du dossier. Télévision, 6, 11-20.

Pereyra, S., 2013. Política y transparencia. La corrupción como problema público Buenos Aires: Siglo XXI.

Pucciarelli, A., 2006. Introducción. In A. Pucciarelli (Ed.). Los años de Alfonsín: ¿El poder de la democracia o la democracia del poder?. Buenos Aires: Siglo XXI. 
Pucciarelli, A., 2011. Menemismo. La construcción política del peronismo neoliberal. In A. Pucciarelli (Comp.). Los años de Menem. Buenos Aires: Siglo XXI.

Quevedo, L. A., 1992. La política bajo el formato televisivo. In H. Schmucler \& M. C. Mata (Eds.). Política y comunicación: ¿hay un lugar para la política en la cultura mediática?. Córdoba: Catálogo, pp.13-20.

Quevedo, L. A., 1999. Política, medios y cultura en la Argentina de fin de siglo. In D. Filmus. Los noventa. Política, sociedad y cultura en América Latina y Argentina de fin de siglo. Buenos Aires: Eudeba, pp.201-224.

Rieffel, R., 1989. Du vedettariat médiatique. Hermès, 4, pp.215-222.

Rinesi, E. \& Vommaro, G., 2007. Notas sobre la democracia, la representación y algunos problemas conexos. In E. Rinesi, G. Nardacchione, \& G. Vommaro. Los lentes de Victor Hugo. Transformaciones políticas y desafíos teóricos en la Argentina reciente. Buenos Aires: Prometeo-UNGS.

Ruiz, F. J., 2001. Las palabras son acciones: Historia política y profesional de La Opinión de Jacobo Timerman (1971-1977) Buenos Aires: Perfil Libros.

Ruiz, F. J., 2005. El señor de los mercados: Ámbito financiero, la City y el poder del periodismo económico de Martínez de Hoz a Cavallo Buenos Aires: El Ateneo.

Sarlo, B., 1997. Siete hipótesis sobre la videopolítica. In Instantáneas: medios, sociedad y costumbres en el fin de siglo. Buenos Aires: Ariel.

Schlesinger, P., 1990. Rethinking the sociology of journalism: Source strategies and the limits of media-centrism. In Public communication: The new imperatives, pp.61-83.

Sidicaro, R., 2001. La crisis del Estado: actores políticos y socioeconómicos en la Argentina (1989-2001) Buenos Aires: Libros del Rojas-Eudeba.

Sivak, M., 2005. El doctor: biografía no autorizada de Mariano Grondona Buenos Aires: Aguilar.

Torre, J. C., 2003. Los huérfanos de la política de partidos: Sobre los alcances y la naturaleza de la crisis de representación partidaria. Desarrollo económico, pp.647-665.

Touraine, A., 1995. Comunicación política y crisis de representatividad. In J.M. Ferry \& D. Wolton. El nuevo espacio público. Barcelona: Gedisa, pp.47-56.

Ulanovsky, C., 1997. Paren las rotativas: una historia de grandes diarios, revistas y periodistas argentinos Buenos Aires: Espasa.

Vommaro, G., 2008a. "Lo que quiere la gente”: los sondeos de opinión y el espacio de la comunicación política en Argentina (1983-1999) Buenos Aires: Prometeo-UNGS.

Vommaro, G., 2008b. Mejor que decir es mostrar: medios y política en la democracia argentina Buenos Aires: UNGS.

Vommaro, G. \& Baldoni, M., 2012. Bernardo y Mariano: las transformaciones del periodismo político en Argentina, de los años ochenta a los años noventa. Mediálogos, Revista de Comunicación Social, 2, pp.59-82.

Weber, M., 1998 [1919]. El político y el científico Madrid: Alianza.

\section{Artículos en periódicos diários}

Al final, lo dejaron solo. 1997. Página 12. Buenos Aires, 15.Jun., p.13.

Bernardo Neustadt. La Plaza del Ni. 2006. Noticias. Buenos Aires, 12.Ago., p.29.

Cadena de la infelicidad, 1990 [Por Bernardo Neustadt]. Ámbito Financiero. Buenos Aires, 30.Mar., p.14.

El día en que Menem asumió la conducción. 1993. La Nación. Buenos Aires, 12.Oct.

El efecto Neustadt. 1990. Somos. Buenos Aires, 18.Abr., pp.20-21.

El Mundo Perdido: Bernardo Neustadt, la hora clave de su sombra. 1992. Noticias. Buenos Aires, 19.Jul.

El Presidente es el primer neustadista [Reportaje a Bernardo Neustadt por Gabriela Cerruti]. 1990. Página 12. Buenos Aires, 8.Abr.

El público es el único que puede terminar con mi éxito [Reportaje a Bernardo Neustadt por Gustavo Javier Wrobel]. 1990. El Cronista Comercial. Buenos Aires, 25.Feb., pp. 6-9.

En comparación, mi autocrítica se va achicando cada día [Reportaje a Bernardo Neustadt por Carlos Ulanovsky]. 1992. La Maga. Buenos Aires, 17.Jun., p.2.

Fue un éxito. Punto. 1990. Ámbito Financiero. Buenos Aires, 9.Abr.

Fustigó Kirchner a quienes le critican superpoderes. 2006. Ámbito Financiero. Buenos Aires, 11.Ago., p.13.

Magdalena contra los periodistas obsecuentes [Reportaje a Magdalena Ruíz Guiñazú por Luis Majul]. 1992. Humor. Buenos Aires, 27.Ene., pp.14-15.

Neustadt vs Grondona. La guerra de los roces. 1992. Somos. Buenos Aires.

Nueva Fuerza. 1990. Página 12. Buenos Aires, 7.Abr.

Qué hay en la trastienda [Por Julio Blanck]. 1990. Clarín. Buenos Aires, 6.Abr., pp. 4.

Saúl ‘querido’ (dueño del ‘no’) [Por Bernardo Neustadt]. 1990. Ámbito Financiero. Buenos Aires, 23.Mar., p. 12.

Soy un simplificador [Reportaje a Bernardo Neustadt por Claudia Selser]. 1990. Página 12. Buenos Aires, 13.Nov., p.10.

Tiempo Nuevo. 1987 [Programa Televisivo]. Buenos Aires. Disponible en: https://youtu.be/HZQfxev6F44. Acceso: 31.Ago.2019.

Tiempo Nuevo. 1989 [Programa Televisivo]. Buenos Aires, 16.May. 


\section{Otras Fuentes}

Diarios y portales de noticias: Clarín, La Nación, Página 12, Ámbito Financiero, El Cronista Comercial, Diario Popular, Infobae.

Revistas: El Periodista de Buenos Aires, El Porteño, Humor, Somos, Extra, Creer, Noticias, Gente, Veintitrés, TXT.

Archivos de prensa gráfica y audiovisuales: Archivo privado del diario Página 12, Archivo de Bernardo Neustadt, disponible en: http://www.bernardoneustadt.org/archivo.htm.

Entrevistas realizadas por la autora a periodistas e informantes claves.

Media power and journalistic notoriety: Bernardo Neustadt and political journalism during the 1990s

ABSTRACT Introduction: Within the context of the reconfigurations suffered by the political and journalistic fields in the nineties in Argentina, the present work looks into the growing power that political journalists began to hold in the construction of social consensus and in the configuration of media and political scenarios. Materials and Methods: In so doing, it performs a sociohistorical analysis of an exemplary case study. The paper reconstructs the career of journalist Bernardo Neustadt, who became a pioneer and a vedette of television political journalism in those years. Also, it focuses on the unique characteristics of the political demonstration promoted by this actor, in 1990, known as the "Plaza del Sí", which contributed to the legitimation of the neoliberal model promoted by the government. Based on these objectives, complementary sources were surveyed: press files, biographies, journalistic books, audiovisual materials and semi-structured interviews with journalists and key informants. Results: The study shows how media notoriety became a form of symbolic capital along with the increasing gravitation of broadcast media. Notoriety began to operate in the political-journalistic field as a form of prestige and social legitimacy. Hence, the holding of this form of capital made it possible for certain journalists to become public figures, whose power was founded in their mass audience. Discussion: The article calls to inquire into the roles played by journalists as opinion makers in the public arena and on the different ways in which media power can be exercised, particularly in situations marked by the discrediting of political institutions and organizations.

KEYWORDS: political journalism; media power; public opinion; political mediatization; notoriety.

This is an Open Access article distributed under the terms of the Creative Commons Attribution Non-Commercial License which permits unrestricted non-commercial use, distribution, and reproduction in any medium provided the original work is properly cited. 